\title{
Readiness to forgive as an educational strategy for the development of emotional intelligence in students
}

\author{
Olga Vasilyeva ${ }^{1, *}$, Nadezhda Blinova $^{2}$ and Tatiana Kondratieva ${ }^{2}$ \\ ${ }^{1}$ Southern Federal University. 344006, st. B. Sadovaya, 105/42, Rostov-on-Don, Russia \\ ${ }^{2}$ Don State Technical University. 344003, Gagarin Square 1, Rostov-on-Don, Russia
}

\begin{abstract}
One of the strategic objectives of education is the development of emotional intelligence. The paper examines the relationship between readiness to forgive and emotional intelligence with the level of subjective control. The study of emotional intelligence was carried out according to the method "Emotional intelligence" (N. Hall), the study of the level of subjective control was carried out according to the method of J. Rotter. To determine the level of readiness for forgiveness, the author's questionnaire "Readiness for forgiveness" was compiled. Readiness for forgiveness creates conditions for the development of a personality as a forgiver as well as the personality of the forgiven person. It appears as a result of deeper understanding of the traumatic situation and the reasons for its occurrence. Readiness to forgive, to our opinion, is a base tool for the transformation of emotional manifestation. We found a significant correlation between the integrative index of emotional intelligence and a level of a readiness for forgiveness. Subjects with a high readiness for forgiveness are capable of efficient regulation of their emotional sphere. Various forms of organization of group work help students to adjust their ideas about readiness for forgiveness, which contributes to the development of emotional intelligence, harmonization of both intrapersonal and interpersonal space. Formation of a deeper and adequate understanding of readiness for forgiveness is an important task of the education.
\end{abstract}

\section{Introduction}

In the modern society, the gap between scientific and technological progress and the emotional development of a person is rapidly increasing. Every day, a person consumes a huge amount of diverse, often contradictory information that does not allow forming a clear hierarchy of goals and values. We all see a destruction of family value as well as the accumulating claims to oneself, to others and to the world. The problem of systematic distortion of information, lack of adequate perception and incorrect semantic reproduction of information content in the learning environment remains relevant at the present time. At the same time, the development of scientific and technological progress leads to a sedentary lifestyle. All these factors are the cause of chronic fatigue, stress, and the degradation of

\footnotetext{
* Corresponding author: vos@sfedu.ru
} 
emotional health. That is why there is a growing interest in research in the field of emotional intelligence, the relationship of emotional intelligence with various personality characteristics, the search for tools for the development of emotional intelligence [1]. Researchers have identified factors that have a significant impact on emotional intelligence. One of the significant factors is an upbringing in a childhood. Andreeva I.N. believes that a "special educational strategy" which is based on a primary attention to child's experiences first and then to his behavior and the events in his life as well as the willingness of the parents to discuss emotional problems, contribute to a better understanding of the child of his own emotions. This strategy develops child's ability to self-regulation and contributes to high emotional intelligence [2-4]. Emotional intelligence can be developed. Andreeva I.N. talks about the possibility of its purposeful development through "emotional education", as well as with the help of specially designed trainings. The emotional intelligence model proposed by D.V. Lucyn, considers EQ as the ability to understand one's own and other people's emotions and control them $[5,6]$. Silenok P.F. emphasizes that emotional self-regulation relieves emotional stress and ensures the development of emotional intelligence and emotional culture of the individual. Emotional intelligence, being one of the components of behavior control, acts as an internal individual resource for emotional regulation of the personality. Different levels of EQ development can have a significant impact on coping with stress and difficult conflict situations in interpersonal communication. The ability to recognize emotions, manage emotions, and transform is the condition for improving emotional health. In this regard, one of the strategic objectives of education is the development of emotional intelligence. We consider the readiness to forgive as the basic tool for transforming emotional manifestations. In the interpersonal relationships, the manifestation of forgiveness can be defined as the step-by-step achieving of the following decisions: 1) rejection of negative emotional and behavioral reactions, as well as destructive thoughts in relation to the person who offended you; 2) encouragement of all kinds of positive manifestations in relation to the offender [7-10]. V. Frankl believed that in suffering and forgiveness, one could find a personal sense. V. Frankl argued that it is important to forgive and not revenge. He spoke about accepting suffering and forgiving the Nazis as a necessary stage in the development of the soul. Western models that are based on the intellectual understanding of the abuser emphasize the importance of recognizing the moral principles that generate forgiveness. The most famous is the Enright's model, described in his works [11-14]. E. Fromm understood forgiveness as a healing, where what helps is love and not the acceptance of a punishment. K. Izard drew attention not only to the granting of forgiveness to the offended, but also to the role of the offender in the process of forgiveness. He emphasized the role of awareness and experience of guilt, which triggers the process of repentance and prompts to ask for forgiveness [15-17]. The problem of forgiveness in theoretical works is achieved not so much as a moral requirement, but as a specific life task. The solution to this problem is necessary in order to: 1) restore relations between people after the offense they have inflicted (betrayal, humiliation, insult, etc.); 2) rebuild one's own life after irreparable damage (killing loved ones, deliberate ruining and/or maiming [18-21]). The readiness to forgive creates the conditions for the development of the personality of both the forgiving and the forgiven and manifests itself with a deeper understanding of the traumatic situation and the reasons for its occurrence [22-24].

Objective of the study: To study a readiness for forgiveness in relation to the emotional intelligence and the level of subjective control.

We proposed two main hypotheses:

1. It is assumed that there is a relationship between emotional intelligence and the level of readiness to forgive;

2. It is assumed that there is a relationship between emotional intelligence and the level of readiness to forgive. 


\section{Methods}

To study emotional intelligence we used N. Hall's methodology "Emotional Intelligence". To study the level of subjective control we used the methodology of J. Rotter. To determine the level of readiness for forgiveness, the author's questionnaire "Readiness for forgiveness" was compiled. For statistical processing of the results we used a modified Shapiro-Franchia test, methods of correlation analysis, and factor analysis.

The forgiveness readiness level test was compiled on the basis of practical work.

\section{Instructions}

Below you will be offered statements that in this way or others reflect various aspects of your life. For each of the statements, you must indicate the degree of your agreement:

Strongly disagree

Mostly disagree

Partly disagree

I am at a loss to answer

Partly agree

Basically agree

I completely agree

\section{Questionnaire}

1. Any problematic situation in my life I get as an experience.

2. The actions of various government agencies make me happy rather than sadden.

3. Any problematic situation upsets me.

4. In my life, there are often situations when I take offense at myself.

5. In my life, there are often situations when I am dissatisfied with myself.

6. I often take offense at other people.

7. I still cannot forgive my father completely.

8. I still cannot forgive my mother completely.

9. I am always happy with my fate.

10. By forgiving others, you encourage bad deeds.

11. I forgive the abuser without any conditions.

12. I feel grateful to my father.

13. I feel grateful to my mother.

14. You can forgive betrayal.

15. You can forgive treason.

16. You can forgive physical abuse.

17. You can forgive murder.

18. Forgiveness does not exclude punishment.

19. I am grateful to fate.

Readiness to forgiveness is defined as the total value of answers to the direct questions: №1, №2, №9, №11, №12, №13, №14, №15 №16, №17; №18, №19 and the total value of answers to the reverse questions: №3, №4, №5, №6, №7, №8, №10 taken with the opposite sign. All these questions determine the strength of discontent, resentment, gratitude, to whom it is directed and how often it manifests itself.

Research subject: Readiness to forgive; the relationship between emotional intelligence and the level of readiness for forgiveness; the relationship of the level of subjective control with the readiness to forgive.

Object of the research: Respondents aged 18 to 24 are students of the Don State Technical University of various specialties. The study involved 99 students, of whom 61 were boys and 38 girls.

In accordance with the goal and hypotheses, the following Research Objectives were set:

Theoretical: 
1. Consider different approaches to studying the phenomenon of forgiveness;

2. Generalize the available concepts of the forgiveness process and, on this basis, develop an author's questionnaire.

Methodical:

1. Form a diagnostic set of methods for the study of emotional intelligence and the level of subjective control;

2. Develop and test the author's questionnaire for researching readiness to forgiveness;

3. Determine the nature and size of the sample, the criteria for its division into groups.

Empirical:

1. Perform an analysis of readiness to forgive and highlight the subjects who declare low, medium and high propensity to forgive;

2. Identify the level of emotional intelligence and the level of subjective control; establish a relationship with the level of readiness to forgive;

3. Perform a correlation analysis of various parameters of the level of subjective control in relation to the readiness to forgive.

\section{Results}

The study involved 99 people, of which 61 were boys and 38 girls. The sample is presented by students of the Don State Technical University. The age of the respondents is from 18 to 24 years old. The average age of the subjects was 21.6 years.

According to the level of emotional intelligence, respondents were divided into three groups: the group with a low level of integrative indicator of emotional intelligence was $66 \%$; with an average level - 29\%; with a high level - 5\%. (Figure 1).

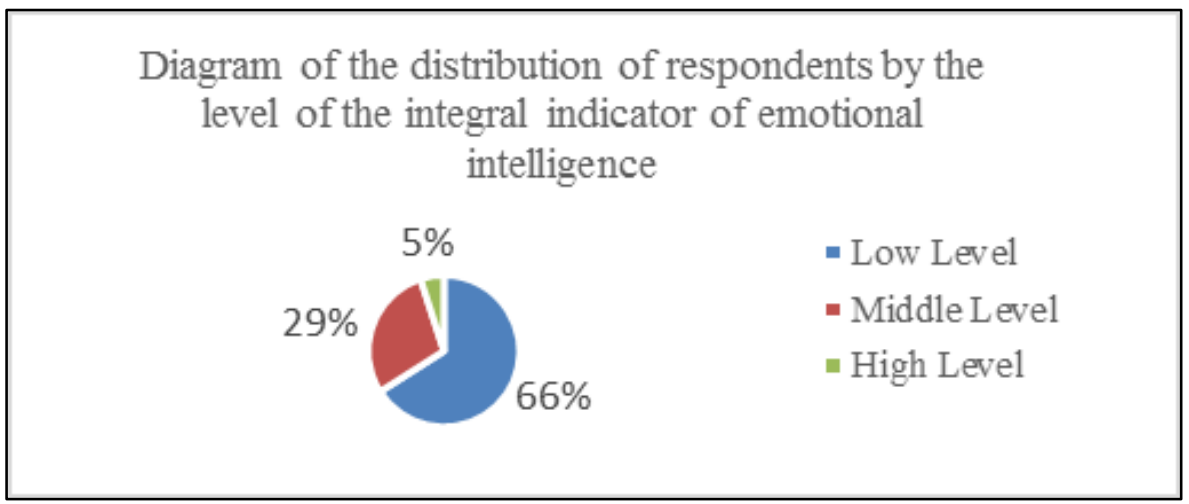

Fig. 1. Diagram of the distribution of respondents by the level of the integral indicator of emotional intelligence.

The questions of the "Readiness to forgiveness" questionnaire have a measuring scale from -3 to +3 points. A digital assessment of the readiness to forgiveness was obtained, therefore statistical analysis procedures can be used with no restriction.

According to the responses to the questionnaire, the respondents were also divided into three groups with high, medium and low levels of readiness to forgive: $19 \%$ of respondents have a low level of readiness to forgive; $69 \%$ - the average level of readiness to forgive; $12 \%$ - a high level of readiness to forgive. (Figure 2) 


\section{Diagram of the distribution of respondents by the level of readiness to forgive}

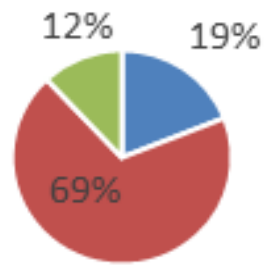

- Low Level

- Middle Level

- High Level

Fig. 2. Diagram of the distribution of respondents by the level of readiness to forgive.

Figure 3 shows a histogram of respondents' response rates to question №1: "I perceive any problematic situation in life as an experience". $52 \%$ of respondents answered "Strongly agree" or "Mostly agree", which means they understand that any traumatic situation lets raise awareness and learn a lesson that promotes a change.

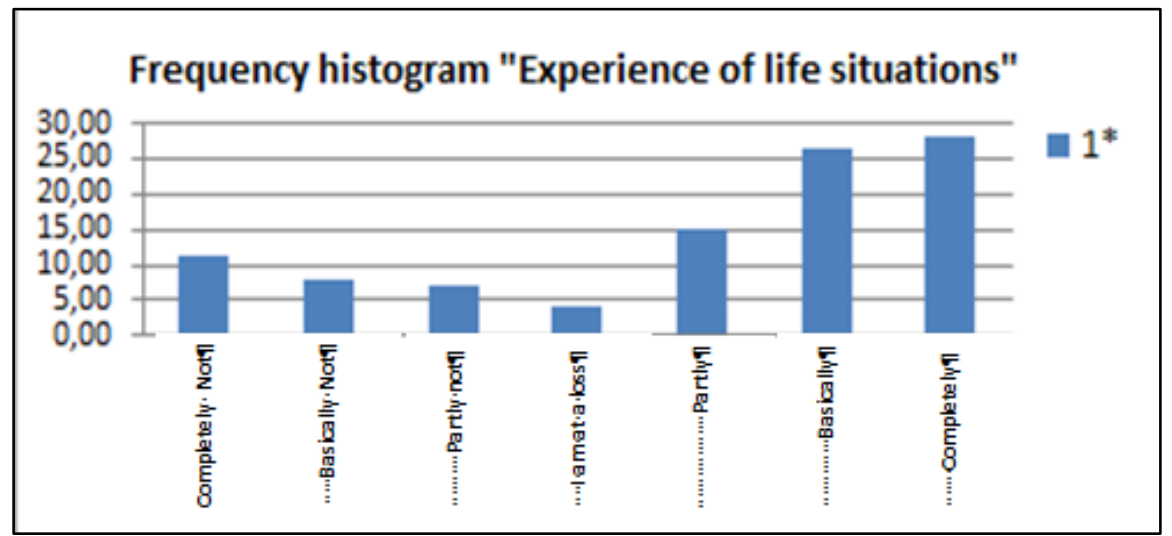

Fig. 3. Histogram of frequencies "Experience of life situations".

Most of the respondents when answering question №5: "In my life there are often situations when I am dissatisfied with myself." answered: "I kind of agree." (Figure 4). 


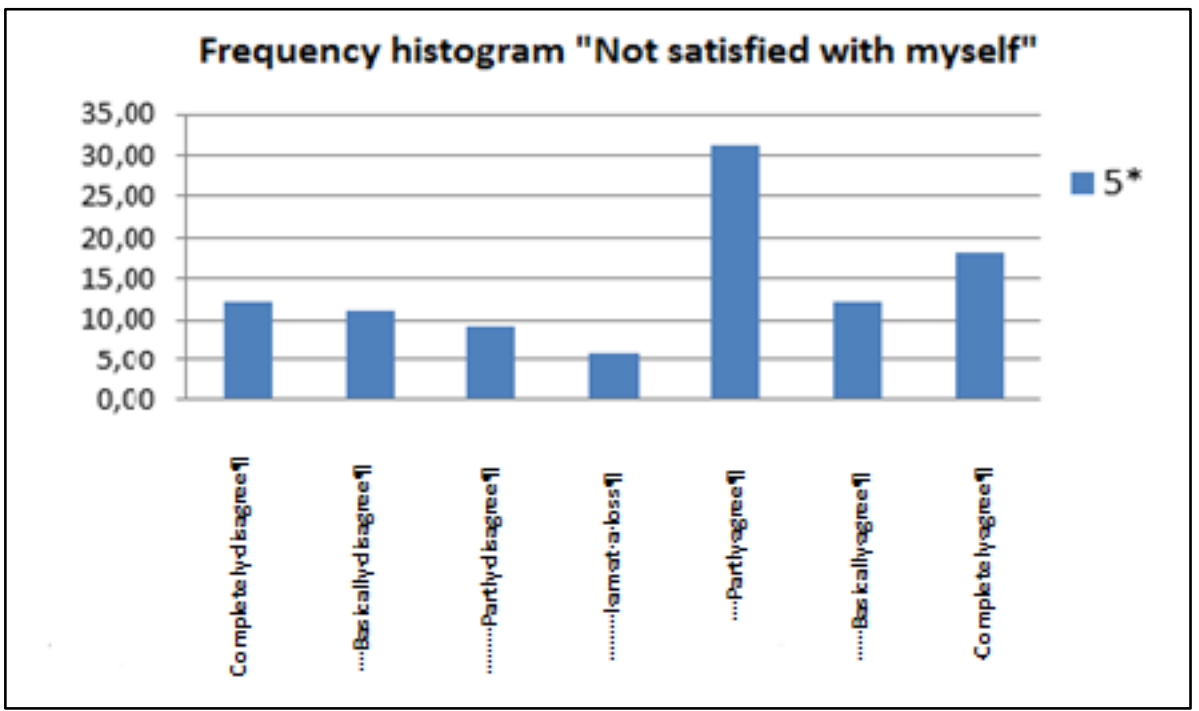

Fig. 4. Frequency histogram "Dissatisfied with myself".

When answering the question No. 7: "I still cannot forgive my father completely" and the question No. 8: "I still cannot forgive my mother completely" $49 \%$ of respondents note that they have completely forgiven their father, $53 \%$ of respondents - forgave the mother completely. At the same time, $15.2 \%$ of respondents do not feel gratitude to their father, and $6.1 \%$ to their mother. (Figure 5).
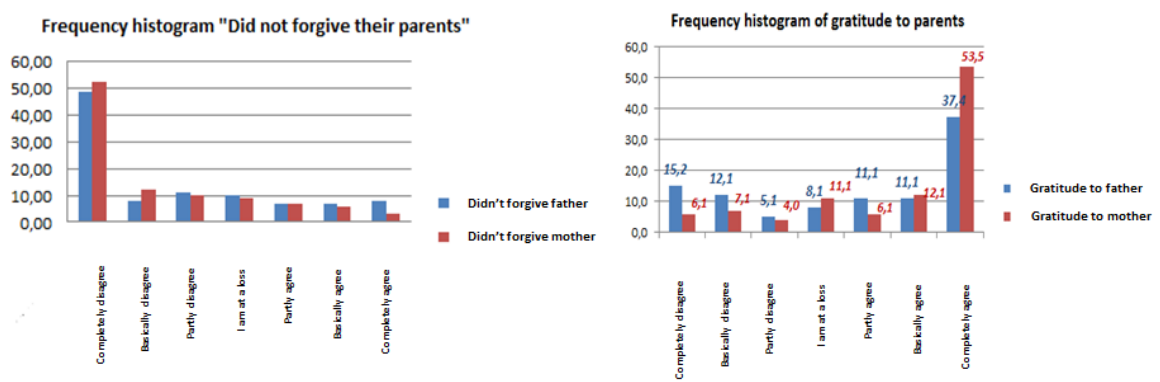

Fig. 5. Frequency histogram "Didn't forgive parents", "Gratitude to parents".

A significant correlation was found between the integrative indicator of emotional intelligence and the level of readiness for forgiveness $(r=0.253 ; p=0.011)$. Thus, we conclude that there is a direct significant relationship between these indicators, that is, the higher the readiness for forgiveness, the higher the assessment of the general level of emotional intelligence.

A significant correlation was established for all scales of emotional intelligence by the $\mathrm{N}$. Hall method and the indicator of general internality according to the J. Rotter method. Relationships of scales: "General internality" and "Emotional awareness" ( $r=0,749 ; \mathrm{p}=$ $\left.1 \cdot 10^{-9}\right)$; "General internality" and "Managing your emotions" $(\mathrm{r}=0,877 ; \mathrm{p}=1$. $\left.10^{-9}\right)$; "General internality" and "Self-motivation" $\left(\mathrm{r}=0,639 ; \mathrm{p}=1 \cdot 10^{-9}\right)$; "General internality" and "Empathy" $\left(r=0,821 ; p=1 \cdot 10^{-9}\right)$; "General internality" and "Recognition of the emotions of other people" $\left(\mathrm{r}=0,639 ; \mathrm{p}=1 \cdot 10^{-9}\right)$; "General internality" and "Integrative level" $\left(r=0,999 ; p=1 \cdot 10^{-9}\right)$. 
The compiled table of interconnection of the integrative indicator of emotional intelligence and the questions of the questionnaire of readiness to forgiveness is quite informative for this study; the results are shown in Table 1. Analyzing the obtained data, we can talk about the statistical relationship of the integrative indicator of emotional intelligence and the answers to the questions of the questionnaire "Readiness for forgiveness". So, for example, the results met the conditions of the criterion of agreement on the following questions of the questionnaire: №1; №5; №7; №8; №9; №12; №1 №3; №15; №16; №17; №18, while for seven questions out of thirteen the level of significance is $\mathrm{p}=0\left(\mathrm{p}=1^{*} 10^{-3}\right)$.

Table 1. Pearson's chi-squared test: "Integrative indicator of the level of EI" and the questions of the questionnaire "Readiness to forgive".

\begin{tabular}{|c|l|c|}
\hline №/№ & \multicolumn{1}{|c|}{ Questions } & Statistics \\
\hline 1 & Experience of life situations & 0.000 \\
\hline 2 & Satisfaction with public services & 0.822 \\
\hline 3 & General anxiety & 0.370 \\
\hline 4 & Offence towards yourself & 0.019 \\
\hline 5 & Dissatisfaction with yourself & 0.000 \\
\hline 6 & Offence towards others & 0.434 \\
\hline 7 & Didn't forgive my father & 0.001 \\
\hline 8 & Did not forgive mother & 0.000 \\
\hline 9 & Happy with the fate & 0.000 \\
\hline 10 & Encouraging bad deeds & 0.311 \\
\hline 11 & Unconditional forgiveness & 0.088 \\
\hline 12 & Gratitude to the father & 0.001 \\
\hline 13 & Gratitude to the mother & 0.000 \\
\hline 14 & Forgive betrayal & 0.134 \\
\hline 15 & Forgive treason & 0.000 \\
\hline 16 & Forgive physical abuse & 0.000 \\
\hline 17 & Forgive murder & 0.002 \\
\hline 18 & Forgiveness Doesn't Exclude Punishment & 0.004 \\
\hline 19 & Grateful to fate & 0.010 \\
\hline
\end{tabular}

The level of internality (externality) was determined by the method of Subjective Control Level of J. Rotter. It should be noted that the higher the level of readiness for forgiveness, the higher the level of internality. The performed correlation analysis shows a significant connection between readiness for forgiveness and the questions of J. Rotter's Subjective Control Level methodology. For example, the following questions have a negative correlation with readiness to forgive: 5. "Getting my desires fulfilled often depends on luck." $(\mathrm{r}=-0.2 ; \mathrm{p}=0444), 8$. "I often feel that I have little influence on what happens to me." ( $\mathrm{r}=$ $0.2602 ; \mathrm{p}=0.009), 18$. "I try not to plan far ahead, because a lot depends on how things turn out." $(\mathrm{r}=-0.2801 ; \mathrm{p}=0.005), 26$. "I often feel that I can not change anything in the existing family relationship." $(\mathrm{r}=-0.3533 ; \mathrm{p}=0.0003), 33$. "Other people were more often to blame for the troubles and failures in my life than myself." $(r=-0.2830 ; p=0.0047), 35$. "In difficult circumstances, I prefer to wait until problems are resolved by themselves." $(r=-0.23 ; p=$ 0.0234). And the following questions: 11 . "When I make plans, I generally believe that I can carry them out." $(\mathrm{r}=0.3529 ; \mathrm{p}=0.0003), 15$. "The good that I do is usually appreciated by others." ( $\mathrm{r}=0.2657 ; \mathrm{p}=0.0079), 19$. "My grades in school depended most on my efforts and my level of preparedness." ( $\mathrm{r}=0.31 ; \mathrm{p}=0.0018), 20$. "In family conflicts, I more often feel guilty about myself than the other side." ( $\mathrm{r}=0.2 ; \mathrm{p}=0.0429), 22$. "I prefer guidance that allows you to decide what to do and how to do it yourself." $(\mathrm{r}=-0.4 ; \mathrm{p}=0.0000), 25$. "At the end, the people who work for the organization are responsible for the poor management of an organization." ( $r=0.199 ; \mathrm{p}=0.0483), 29$. "What happens to me is the work of my own hands." ( $\mathrm{r}=0.24 ; \mathrm{p}=0.0165), 32$. "More often than not, I can get what I want from my family 
members." ( $r=0.2792 ; \mathrm{p}=0.005), 37$. "I feel that the happiness of my family depends on me more than on anyone else." ( $\mathrm{r}=0.3265 ; \mathrm{p}=0.001)$, 39. "I always prefer to make a decision and act on my own, rather than relying on the help of other people or fate." $(\mathrm{r}=0.36 ; \mathrm{p}=$ $0.0003), 44$. "Most of the failures in my life came from inability, ignorance or laziness and little depended on luck or bad luck." $(\mathrm{r}=0.2 ; \mathrm{p}=0.04)$ have a positive correlation coefficient with readiness to forgive.

Thus, the parameters of internality (externality) are essential in the development of readiness for forgiveness in students, since it is important to shift the focus of attention from others to oneself and form personal responsibility for events in his life.

\section{Conclusions}

The study revealed that the majority of subjects have an average and low level of the integral indicator of emotional intelligence. Subjects with a high level of emotional intelligence are more capable of recognizing the emotions of others, showing empathy, and managing their emotions. Subjects with a high readiness to forgive are capable of efficient regulation of their emotional sphere.

The division into groups by gender did not reveal differences, both in the integrative indicator of the level of EI, and in indicators for all scales of N. Hall's methodology.

Various forms of organization of group work help participants adjust their ideas about readiness for forgiveness, which contributes to the harmonization of both intrapersonal and interpersonal space. The readiness to forgive can act as a mechanism for emotional and behavioral regulation, which has positive consequences in the form of strengthening the physical and emotional health of a person.

Formation of a deeper adequate understanding of readiness for forgiveness is an important task of the education. Consequently, one of the strategic tasks of the educational process is the development of emotional intelligence through the readiness to forgive.

The results of this research can be used both in educational and psycho-corrective work with students and can be included in the sections of theoretical and practical courses in communication psychology, conflict psychology, family psychology and health psychology.

\section{Prospects for further research}

Proposition of guidelines for the development of emotional intelligence in students through the formation of awareness, responsibility and learning to forgive.

Conducting various forms of group work that would improve the understanding of forgiveness process, contributing to the harmonization of both the intrapersonal and interpersonal space of students.

Development of practical recommendations on the organization of teaching and educational activities in universities

\section{References}

1. N. Blinova, O. Vasilyeva, T. Kondratieva, Research of social and psychological aspects of forgiveness (XVI European congress of psychology, 2019)

2. G.F. Bachman, L.K. Guerrero, Communication Reports 19, 45-56 (2006) https://doi.org/10.1080/08934210600586357 
3. A.R. Beck, L.M. Ruhlmann, J.A. Durtschi, C.C. Brown, The American Journal of Family Therapy 45(5), 250-263 (2017) https://doi.org/10.1080/01926187.2017. 1365664

4. S.R. Braithwaite, E.A. Selby, F.D. Fincham, Journal of Family Psychology 25, 551-559 (2011) https://doi.org/10.1037/a0024526

5. R.G. Cowden, E.L.Jr. Worthington, S. Joynt, C. Jakins, South Africa Journal of Psychology 49, 403-416 (2019) https://doi.org/10.1177/2F0081246318807800

6. W.G. Graziano, M.M. Habashi, B.E. Sheese, R.M. Tobin, Journal of Personality and Social Psychology 93, 583-599 (2007) https://doi.org/10.1037/0022-3514.93.4.583

7. T. Hashimoto, K. Karasawa, The Japanese Journal of Experimental Social Psychology 51, 104-117 (2012)

8. J.N. Hook, E.L. Worthington, S.O. Utsey, D.E. Davis, J.L. Burnette, Counseling and Values 57, 109-124 (2012) https://doi.org/10.1002/j.2161-007X.2012.00012.x

9. H.D. Johnson, M.A. Wernli, J.C. LaVoie, The Journal of Genetic Psychology 174, 291315 (2013) https://doi.org/10.1080/00221325

10. K. Kaleta, J. Mróz, Roczniki Psychologiczne/Annals of Psychology 21, 147-162 (2018) https://doi.org/10.18290/rpsych.2018.21.2-3

11. J.M. Leunissen, D. De Cremer, C.P.R. Folmer, M. Van Dijke, Journal of Experimental Social Psychology 49, 315-324 (2013) https://doi.org/10.1016/j.jesp.2012.12.005

12. M.E. McCullough, F.D. Fincham, J.A. Tsang, Journal of Personality and Social Psychology 84, 540-557 (2003) https://doi.org/10.1037/0022-3514.84.3.540

13. J. Mróz, K. Kaleta, E. Sołtys, Current Psychology, 1-9 (2020) https://doi.org/10.1007/s12144-020-00838-6

14. G. Nudelman, A. Nadler, Personality and Individual Differences 116, 191-200 (2017) https://doi.org/10.1016/j.paid.2017.04.048

15. L. Rey, N. Extremera, Terapia Psicológica 34, 103-110 (2016) https://doi.org/10.4067/S0718-48082016000200003

16. M. Schmitt, M. Gollwitzer, N. Förster, L. Montada, The Journal of Social Psychology 144, 465-486 (2004) https://doi.org/10.3200/SOCP.144.5.465-486

17. P. Strelan, T. Covic, Journal of Social and Clinical Psychology 25, 1059-1085 (2006) https://doi.org/10.1521/jscp.2006.25.10.1059

18. P. Strelan, J.C. Karremans, J. Krieg, British Journal of Social Psychology 56, 161-180 (2017) https://doi.org/10.1111/bjso.12173

19. J. Strickland, K. Martin, A. Allan, M.M. Allan, An International Journal on Personal Relationships 12, 68-90 (2018) https://doi.org/10.5964/ijpr.v12i1.286

20. S. Takaku, The Journal of Social Psychology 141(4), 494-508 (2001) https://doi.org/10.1080/00224540109600567

21. L.Y. Thompson, C.R. Snyder, L. Hoffman, et al, Journal of Personality 73, 313-359 (2005) https://doi.org/10.1111/j.1467-6494.2005.00311.x.

22. L. Veenstra, B.J. Bushman, S.L. Koole, Current Opinion in Psychology 19, 98-103 (2018) https://doi.org/10.1016/j.copsyc.2017.03.014

23. C.V. Witvliet, L.R. Luna, E.L.Jr. Worthington, J.A. Tsang, Frontiers in Psychology 11, 1-12 (2020) https://doi.org/10.3389/2Ffpsyg.2020.00284

24. E.L. Worthington, C.V.O. Witvliet, P. Pietrini, A.J. Miller, Journal of Behavioral Medicine 30, 291-302 (2007) https://doi.org/10.1007/s10865-007-9105-8 